Review

\title{
Early childhood caries in Kuwait: review and policy recommendations
}

R.E. Morris, ${ }^{1}$ G. Gillespie, ${ }^{2}$ A. Dashti, ${ }^{\prime}$ N.S. Gopalakrishnan ${ }^{3}$ and F. Al-Za'abi'

\section{Introduction}

The terminology with regard to the presence of dental caries in young children, its varying etiologies and clinical manifestations still needs to be clarified. For the purpose of our paper, the presence of dental caries in young children is identified under the general title of early childhood caries (ECC). However, when citing specific studies, the terminology and criteria employed by the respective authors are used.

Early childhood caries, also referred to as nursing caries, baby-bottle caries or nursing-bottle caries, is a particularly aggressive form of dental caries, which can involve the primary incisor teeth within a few months of their eruption. While an accepted consensus definition for ECC does not exist, it is generally agreed that ECC is a form of rampant caries associated with inappropriate bottle-feeding or breastfeeding $[I]$.

ECC is associated with prolonged and frequent exposure to fermentable carbohydrates. In Western societies, the primary risk factor is considered to be the use of a naptime or night-time baby bottle that contains a fermentable carbohydrate food such as milk, milk with sugar, sweetened milk formula, fruit juice, sugar solution or other sweetened solutions [ 1$]$. Sleeping with the mother's nipple in the mouth has been identified as a primary risk factor in one African country.

The purpose of our study was to review the prevalence of early childhood caries in Kuwait over the past 10 years, to discuss possible local risk factors and to make policy recommendations for interventions at the national and community levels. A comprehensive review of infant caries and prevalence rates around the world is available in the Journal of public health dentist$r y, 1996,56(1)$.

\section{Clinical foaturos of infant caries}

The initial lesion of infant caries is a band of white chalky demineralization along the gum line in the maxillary incisors soon after eruption. It may appear as pitting of the enamel surface in the same region. As the lesion progresses it can become pigmented to light yellow, brown and then black. The initial lesion can also appear on the palatal surface and, in extreme cases, at the incisal edge. As the lesion progresses, it will extend around the circumference of the tooth,

'Oral Healti Services, Ministry of Publlc Moalth, Nuwain.

${ }^{2}$ Hawalli School Health Programme, Kuwait.

3 Jahra School Health Programme, Kuwait.

Received: 08104/99; accepted: 16/05/99 
forming a black collar with extensive hard tissue loss. The tooth at this stage may be at risk of crown fracture.

Following the maxillary incisors, the first molars are the next teeth most likely to be affected. Second molars and canines may also become involved depending on the severity of the caries attack. This pattern of involvement follows the eruption sequence of the primary teeth. Teeth erupting after the discisntinuation of the cariogenic habit are less affected than those present during the habit. It is possible to verify the feeding history by correlating the severity of caries with the eruption sequence. The lesions are usually symmetric for right and left and upper and lower teeth, with the exception of the mandibular incisors. In both breastfed and bottle-fed children, the nipple (natural or artificial) rests against the palate during sucking. During this process, the mandibular incisors are protected by the tongue. The tongue extends anteriorly over the lower anterior teeth to form an oral seal. The milk or other fluids then pool around the maxillary incisors. flowing around the medial aspect of the tongue and bathing the occlusal and lingual surfaces of posterior teeth.

\section{Methods}

Both published and unpublished data on early childhood caries were reviewed to determine any trend since 1985 . Original data were re-examined to determine if the term ECC was applicable. Additional published research in Kuwait was examined to assess possible risk factors within the local context.

\section{Epidomiology of early ohildhood carles}

Five prevalence studies of caries in infants and the very young have been carricd out in
Kuwait since 1985 (Figure 1) [2-6]. An additional study of the feeding habits of an atrisk group has been done [7]. In 1985 , Soparkar et al. found infant caries in $11.5 \%$ of children ( $n=4653$, age $4-6$ years) nationally, with a prevalence of $13.8 \%$ in $\mathrm{Ku}$ waiti schoolchildren [2]. In 1989, Al-Dashti et al. found a prevalence rate of $19 \%(n=227$, age $18-48$ months $)$ in a group of infants in a health care centre of the Bayan District and born in the national maternity hospital [3]. In 1993, in the national oral health survey of children, the prevalence of anterior tooth caries was reported to be $47 \%$ among 4-year-olds ( $n=$ 542 Kuwaitis, 5 non-Kuwaitis) and $52 \%$ among 6-year-olds ( $n=1141$ Kuwaitis, 81 non-Kuwaitis) [4]. Only $19 \%$ of the former and $9 \%$ of the latter were caries-free in the primary dentition. Also in 1993, Murtomaa et al. examined 450 children (age 3-7 years) at a private English-language school and found $22 \%$ of primary anterior teeth decayed and up to $43 \%$ of primary molars

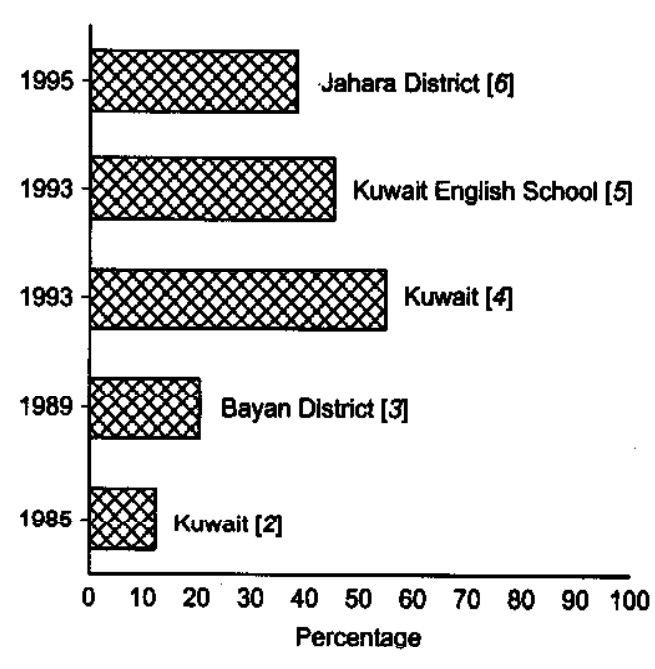

Figure 1 Percentage of children with early childhood caries by site and year. Kuwalt

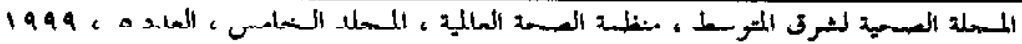


decayed [5]. In 1995, the Jahra Health Region school-based oral health programme reported a $35.5 \%$ prevalence in a survey of kindergarten children $(n=290)$ [6].

While the 1985, 1989 and 1995 surveys were carried out specifically to examine the prevalence of infant caries, the other "two studies simply reported the prevalence of anterior or posterior primary teeth caries. Obviously, prevalence rates would vary depending on criteria used to classify the condition seen as infant caries in these studies.

\section{Discussion}

A substantial body of data exists in Kuwait showing a dramatic increase in early childhood caries since 1985. The national survey of 1993 showed an increase in the decayed, missing, filled permanent teeth (DMFT) index of 12- and 15-year-olds of $30 \%$ and $33 \%$ respectively from 1982 . It also showed a reduction in the percentages of caries-free children from $20.6 \%$ in 5 year-olds in 1982 to $19.0 \%$ at age 4 years in 1993; and an increase in decayed, filled primary teeth (dft) from 4.2 at age 5 years to 4.6 at age 4 years. It also reported a $53 \%$ increase in decayed, filled primary tooth surfaces (dfs) at age 6 years from 7.6 in 1982 to 11.6 in 1993 (Figures 2 and 3) $[4,8]$.

During this period, Kuwait has had a national health care system including free oral care, and two health regions have participaled in systematic oral disease prevention and curative care programmes for kindergarten and primary-school children. In one of these health regions with schoolbased coverage, the dfs index at age 4 years in 1993 was 7.4 versus 7.3 nationally, and the percentages of caries-free children at ages 4 years and 6 years were $15 \%$ and $5 \%$ versus $19 \%$ and $9 \%$ nationally [4]. The dfs index at age 4 years in the second region with coverage was 6.8 and the percentages of caries-free children in the two age groups were $17 \%$ and $12 \%$ respectively. It appears that the first noted school-based programme did not have any "halo" pre-

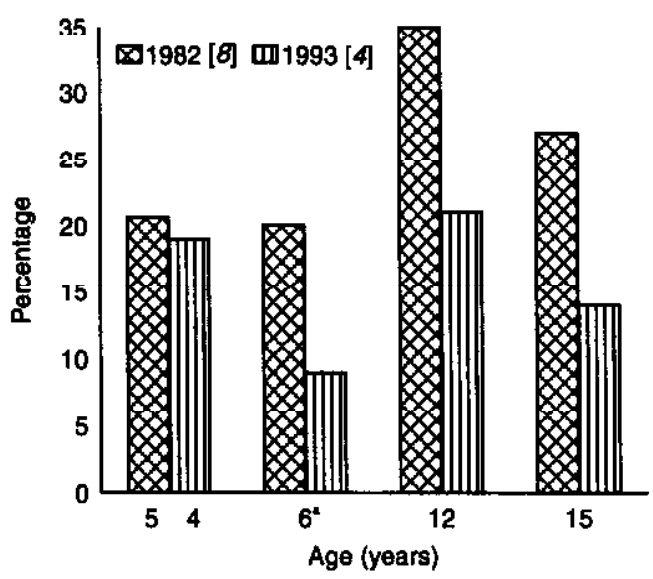

Deciduous and permanent teeth

Figure 2 Percentage of chlldren tree of carles at selected ages in Kuwalt, 1982 and 1993

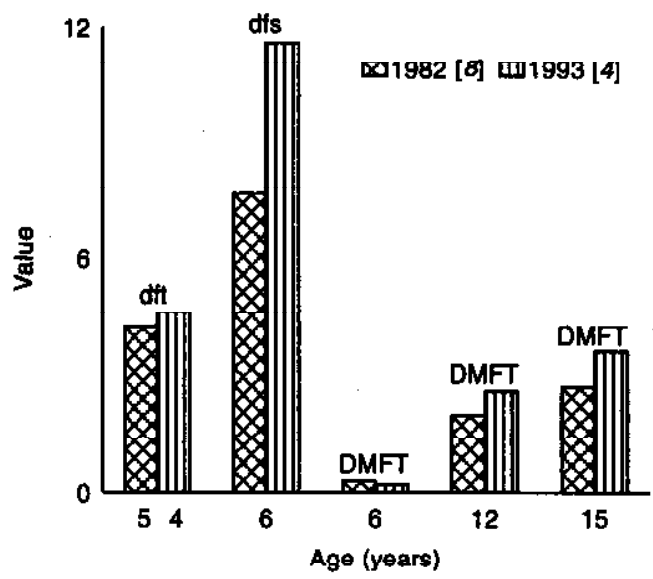

Figure 3 dft, dfe, DMFT in children in Kuwait, 1982 and 1993 
ventive effect among preschool children prior to the survey period.

In the 1989 study of Al-Dashti et al., associations between risk factors and infant caries were examined [3]. Significant associations were found: breastfed children were significantly more likely to be cariesfree than those bottle-fed from birth; infant caries was positively associated with atwill breastfeeding at night after 6 months of age; bottle-fed infants were more likely to develop infant caries, with prevalence rising the later the practice continued; lower levels of caries were found in infants of parents of higher socioeconomic levels.

On the other hand, Murtomaa et al., in a study carried out in an English language school where children would be considered from the higher socioeconomic levels, demonstrated a relatively high prevalence rate of ECC [5]. Babeely et al, described a strong association between disease severity and abusive feeding practices (bottle as pacifier, at-will breastfeeding, sleeping with bottle, practice of these habits over time) in their study of infant caries [7].

The mean dmft (2.9) of preschool children aged 3-7 years in the Murtomaa study and the mean decayed, extracted filled primary teeth (deft) in children aged 4 years of the 1993 national study (4.6) are higher than rates in the Nordic countries in general, where the mean dmft scores vary between 0.3 and 2.1 [9-13]. Iceland is an exception, with mean dmft scores of 2.4-4.1 for 4- to 6 -year-olds $[14,15]$. In Finland, for instance, in 1987 the mean dmft of 3- to 7year-olds was 1.3 [I2]. The total proportion of caries-free children in Kuwait in 1993 at 4 years $(19 \%)$ and 6 years $(9 \%)$ is smaller than in Nordic countries, where the proportion of caries-free preschool children varies between $58 \%$ and $83 \%[9,11-13]$.

In the United States, infant caries rates remain dramatically high among certain minority populations, but the problem also exists within the general population, in spite of extensive public education and professional awareness [16].

Causes or factors involved in this rise in disease prevalence must be identified. At present, mainly anecdotal information is available, but Kuwait has clearly dramatically changed its cultural habits since the 1970 s rise in oil prices. Almost all families have maids and nannies who bear a major responsibility in caring for young children. Bottle-feeding in children less than 24 months old appears favoured over breastfeeding (Table 1), moreso in younger mothers and working mothers (Tables 2 and 3 ) [17]. Educated women are the least likely to breastfeed. Consumption of sweets and

Table 1 Feeding method by Infant age"

\begin{tabular}{|c|c|c|c|c|c|}
\hline $\begin{array}{l}\text { Age } \\
\text { group } \\
\text { (months) }\end{array}$ & $\begin{array}{c}\text { Breast } \\
(\%)\end{array}$ & $\begin{array}{c}\text { Bottle } \\
(\%)\end{array}$ & $\begin{array}{l}\text { Both } \\
(\%)\end{array}$ & $\begin{array}{c}\text { Woaned } \\
(\%)\end{array}$ & $\begin{array}{l}\text { Total } \\
\text { No. }\end{array}$ \\
\hline$<6$ & 13.7 & 57.4 & 28.9 & 0.0 & 2197 \\
\hline $6-12$ & 10.3 & 72.4 & 17.2 & 0.2 & 1284 \\
\hline $12-24$ & 9.0 & 81.4 & 7.5 & 2.2 & 1641 \\
\hline Total & 11.3 & 68.9 & 19.1 & 0.7 & 5122 \\
\hline
\end{tabular}

source: [17]

Table 2 Feeding method by mother's age*

\begin{tabular}{lrrrrr}
\hline $\begin{array}{l}\text { Age } \\
\text { group } \\
\text { (years) }\end{array}$ & $\begin{array}{c}\text { Breast } \\
(\%)\end{array}$ & $\begin{array}{c}\text { Bottle } \\
(\%)\end{array}$ & $\begin{array}{c}\text { Both Weaned } \\
(\%)\end{array}$ & $\begin{array}{r}\text { Total } \\
\text { No. }\end{array}$ \\
\hline$<20$ & 6.6 & 75.4 & 18.0 & 0.0 & 183 \\
$20-30$ & 9.3 & 72.8 & 17.1 & 0.9 & 2895 \\
$30-40$ & 14.1 & 63.3 & 21.9 & 0.7 & 1838 \\
$40+$ & 19.4 & 56.8 & 23.8 & 0.0 & 206 \\
Total & 11.3 & 68.9 & 19.1 & 0.7 & 5122 \\
\hline
\end{tabular}

aGource: [17]

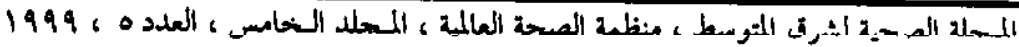


desserts is reported high [18]. The bottle as pacifier is considered a common habit. Petersen et al. reported $66 \%$ of first-grade children consuming chocolate bars and soft drinks several times a day. Sweets are actually passed out in some dental offices and by dentists as rewards.

Similar rapid uncontrolled caries in primary dentition in South-East Asia has been explained partly by the increased consumption of foods containing sugar [19]. This is one explanation that could also hold true in Kuwait. A recent study in Guatemala showed a correlation between malnutrition and primary teeth caries [20]. Early colonization of the child's mouth through the transmission of mutans streptococcus from the parents is another concern [21-23] and relevant in a country with known poor oral hygiene [24]. The discontinuation of national community water fluoridation in $\mathrm{Ku}-$ wait in the beginning of the 1980s is also a factor to consider in this change in the caries rates (Figure 4).

The national oral health service of $\mathrm{Ku}-$ wait was repair/extraction-based prior to 1992. Only limited prevention programmes were available to schoolchildren before 1994. Those programmes reached less than $20 \%$ of kindergarten and primary-school children. Preventive programmes have now

Table 3 Feeding mothod by mother's working status:

\begin{tabular}{lccccc}
\hline $\begin{array}{l}\text { Working Breast } \\
\text { status }\end{array}$ & $\begin{array}{c}\text { Bottle } \\
(\%)\end{array}$ & $\begin{array}{c}\text { Both } \\
(\%)\end{array}$ & $\begin{array}{c}\text { Weaned } \\
(\%)\end{array}$ & $\begin{array}{c}\text { Total } \\
\text { No. }\end{array}$ \\
\hline Working & 6.5 & 74.8 & 18.4 & 0.3 & 2129 \\
Not & & & & & \\
$\quad$ morking & 14.7 & 64.6 & 10.7 & 1.0 & 2003 \\
Total & 11.3 & 68.9 & 19.1 & 0.7 & 5122 \\
\hline
\end{tabular}

-Source: [17]

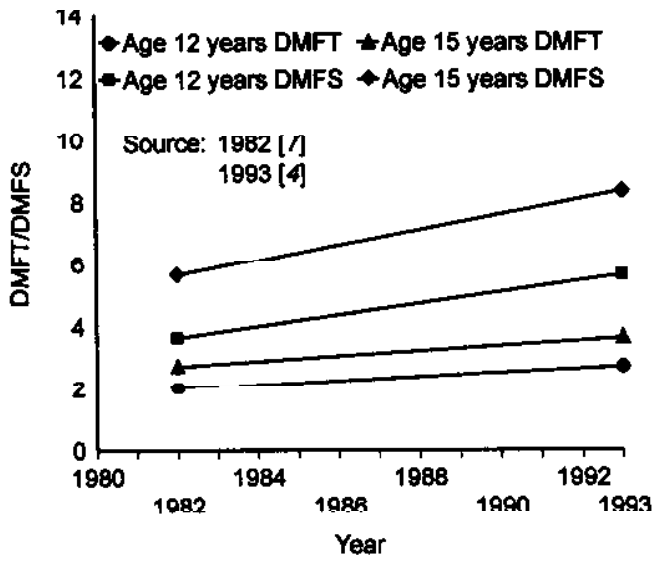

Figure 4 DMFT and DMFS in children aged 12 years and 15 years in Kuwait, 1982 and 1993

been expanded to reach over $90 \%$ of kindergarten and primary-school children in government schools. However, substantial numbers of Kuwaitis and non-Kuwaitis in private schools remain outside this scheme.

No systematic preventive or care programme exists for infants and preschoolers. Care for the majority of preschoolers remains episodic, delivered at district health centres or by paediatric dentists in the private or public sector. Attendance at these clinics by the very young for prevention is considered minimal [4].

\section{Recommendations}

The World Health Organization (WHO), in collaboration with the International Dental Federation, adopted as a global goal for oral health that by the year $2000,50 \%$ of 5 to 6-year-olds should be caries-free [25]. On the basis of the studies reviewed here, achievement of that goal seems remote. A notable public health problem has developed among very young children in Kuwait 
in recent years with this significant increase in infant caries. There is a need for organized oral health care, passive prevention (community fluoridation) and early intervention programmes for very young children, with regular guaranteed oral examinations.

Research is needed in several areas to reduce the incidence and prevalence of ECC in Kuwait.

- The primary risk factors must be identified.

- A community-based, early intervention programme involving health practitioners, parents and other caregivers should be developed in which the concept of anticipatory guidance to provide early interventions is clearly examined.

- Direct early prevention interventions such as fluoride tablets/drops, fluoride varnishes or similar vehicles must be examined.

- A national health promotion and education methodology to introduce messages, training and concepts of prevention and care to the target groups must be developed. It should effect long-term behavioural change in the parents, caregivers, health professionals and other involved individuals. The easiest and largest effect can be gained by the re-introduction of community fluoridation. Such a measure also follows the public health precept of obtaining the greatest community benefits at the least cost.

\section{Anticipatory guidance for oral health}

The Kuwait national health care system does not allow for the oral health team (primarily dentists) to routinely intervene in the care of infants and the very young. With the recent expansion of preventive pro- grammes, most Kuwaiti public school kindergarten children are now enrolled in disease prevention programmes. There is, however, no programme or policy for very young children. The anticipatory guidance (AG) model used in preventive medicine provides a real alternative to a programme in which only the oral health team intervenes in this epidemic.

The AG for oral health model should be implemented throughout the health care system and should not be considered an item of dental care. AG can be broadly defined as the process of providing practical, developmentally appropriate, health information about children to their parents on anticipation of significant physical, emotional and pychological milestones. Oral health is part of general health and the AG approach for early oral health promotion/ disease prevention should be practised by health professionals in all areas, such as obstetrics, gynaecology, paediatric care and well-baby care. Similarly. early intervention might be provided at well-baby units, paediatric units and dental units.

The AG model has been used for more than 50 years [26]. Health professionals guide parents regarding impending change, teaching them their roles in maximizing their children's developmental potential, identifying the particular needs of the child. Health professionals in well-care clinics have been using $A G$ for years providing physical examinations, immunizations, with AG keyed to the child's development. The process is interactive, with the provider adjusting the information based on parents' responses. The development of the AG model has been hastened in North America by the realization that:

- early intervention and prevention is cost-effective; 
- parents have an increasing need for health information;

- the rising number of single parents, working mothers and young parents separated from family networks that have historically provided and transferred child-rearing information. Such changes have also occurred in Kuwait over the past few decades, including the wide use of non-health-oriented nannies.

A significant percentage of the physical problems that beset children and parents are related to lifestyle choices [26]. Reisinger and Bires state that children's concepts of health and illness, like most behavioural characteristics, are formed by observing how parente conduct their lives [26]. Parents increase the potential for future health problems in their children by exposing them to habits that are unwholesome. Health professionals, by their collective position in society and their individual interaction with parents, can facilitate helping families adopt more healthy ways of living.

The Amerioan Aeademy of Pediatrice argues that preventive paediatrics is the core of quality medical care for children and that counselling and discussion is the most important element of child health care. Within advanced oral health care systems worldwide, preventive dentistry has become the sine qua non. In Kuwait, this preventive emphasis has only recently taken hold in the oral health sector and has not filtered to the very young, pregnant women, mothers or the allied and medical health sector dealing with these groups. When oral disease prevention programmes have been advocated for Kuwaiti children over the past 15 ycars, infants and very young children have not been included in the policies and programmes.
In the United States, the following topics are included in current recommendations by the American Academy of Pediatric Dentistry for AG: oral development, fluoride adequacy, oral hygiene and health habits, diet and nutrition, injury prevention [27].

For Kuwait some key behavioural messages in AG to prevent oral diseases and conditions are:

- Contents of the last bottle of the night to be plain water with no sugar added.

- Sleeping with a bottle or the breast in the mouth to be discouraged.

- Cleaning the child's teeth and gums with fluoride toothpaste to be encouraged.

- A fluoride supplement to be encouraged.

- Injury prevention to be promoted. Some key early interventions might be:

- fluoride drops or lozenges

- fluoride varnishes

- diet control

- sealants.

\section{Conclusion}

It is evident from the disease data presented that existing infant oral care guidance is inadequate to prevent early childhood caries in Kuwait, and the country will not reach the WHO goal of $50 \%$ of 5-6-year-olds to be caries-free in the year 2000 . While there are no studies documenting early intervention models, it remains clear that change must take place and in Kuwait, the change must occur throughout the health sector. Dentists will play a minor clinical role. The dental profession's primary role will be to support the development of the AG model, advocate inclusion of the very young in dis- 
ease prevention programmes, and promote passive fluoride interventions nationally, e.g. community water fluoridation or salt fluoridation. The problem rests with all those associated with maternal and child health and primary care, and immediate action should be taken in conjunction with these groups to stabilize and reduce this disease burden.

\section{References}

1. Milnes AR. Description and epidemiology of nursing caries. Journal of public health dentistry, 1996, 56(1):38-50.

2. Soparkar $P$ et al. Nursing bottle syndrome in Kuwait. Journal of dental research, 1986, 65:745.

3. Al-Dashti AA, Williams SA, Curzon MEJ. Breastfoeding, bottlo-feeding and dental caries in Kuwait, a country with low-fluoride levels in the water supply. Community dental health. 1995. 12:42-7.

4. Skougaard MR, Vigild M. Kuwait national oral health survey: oral health of 4-, 6-, 12-, and 15-yoar-old ohildren in kindergartens and public schools in Kuwait. Kuwait, Ministry of Public Health, 1993.

5. Murtomaa $\mathrm{H}$ et al. Carles experience in a selected group of children in Kuwait..Acta odontologica Scandinavica, 1996, 53:389-91.

6. Jahra school health programme. Annual report 1995/96. Kuwait, Ministry of Public Health, 1996.

7. Babeely $\mathrm{K}$ et al. Severity of nursing-bottle syndrome and feeding patterns in Kuwait. Community dentistry and oral epidemiology, 1989, 17:237-9.

8. Glass RL. National Dental Health Survey of Children. Kuwait, Ministry of Public Health, 1982.

9. Petersen PE. Oral hoalth bohavior of 6 year-old Danish children. Acta odontologica Scandinavica, 1992, 50:57-64.
10. Marthaler TM. Caries status in Europe and predictions of future trends. Caries research, 1990, 24:381-96.

11. Stecksen-Blicks $C$, Holm AK, Mayanagi $H$. Dental caries in Swedish 4-year-old children. Swedish dental journal, 1989, 13:39-44.

12. Kerosuo H, Honkala E. Carles experlence in the primary dentition of Tanzanian and Finnish 3- to 7-year-old children. Community dentistry and oral epidemiology, 1991, 19:272-6.

13. Sönju Clasen $A B$, von der Fehr FR, Kant van Daal JM. Caries prevalence of klndergarten children Salzgitter and Oslo. Caries research, 1992, 6:201-4.

14. Holbrook WP et al. Caries prevalence, streptococcus mutans and sugar intake among 4-year-old urban children in Iceland. Community dentistry and oral epidemiology, 1989, 17:292-5.

15. Saemundsson SR et al. Dental caries and streptococcus mutans in a rural child population in Iceland. Scandinavian journal of dental research, 1992, 100:299303.

16. Barnes GP et al. Ethnicity, location, age, and fluoridation factors in baby-bottle tooth decay and caries prevalence of Head Start children. Public health reports, 1992, 107(2):167-73.

17. Al-Rashoud R, Farid S, eds. Kuwait child health survey. Kuwait, Ministry of Public Health, 1991.

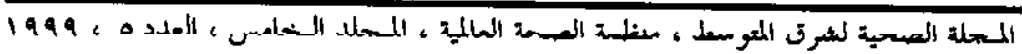


18. Petersen PE et al. Dental knowledge, attitudes and behavior among Kuwaiti mothers and school teachers. Journal of pedodontics, 1990, 14(3):158-64.

19. Holm AK. Caries in the preschool child: international trends. Journal of dentistry, 1990, 18:291-5.

20. Alvarez JO et al. A longitudinal study of dental caries in the primary teeth of children who suffered from intant malnutrition. Journal of dental research, 1993, 72(12):1573-6.

21. Axelsson $\mathbf{P}$ et al. Integrated caries prevention: effect of a needs-related preventive program on dental caries in children. Caries research, 1993, 27(suppl. 1):8394.

22. Johnsen DC et al. Caries pattorng in Head Start children in a fluoridated com- munity. Journal of public nearth dent/stry, 1984, 44(2):61-6.

23. Brown JP, Junner C, Liew V. A study of streptococcus mutans levels in both infants with bottle caries and their mothers. Australian dental journal, 1985 , 30(2):96-8.

24. Kuwait health survey. Kuwait, Ministry of Public Health, 1986.

25. WHO global indicators of oral health. Geneva, World Health Organization, 1981.

26. Reisinger KS, Bires BS. Anticipatory guidance in pediatric practice. Pediatrics, 1980, 68(6):889-92.

27. American Academy of Pediatric Dentistry. Special issue: reference manual 1994-1995. Pediatric dentistry, 19941995, 16(7):1-96.
Note from the Editor

A complete list including the names of our respected reviewers for the year 1999 will be published in the next issue of the Journal. The author and subject indexes for Volume 5(1999) will be distributed as an insert in Arabic, English and French with the next issue. 